\title{
The Exchange Rate Response Puzzle
}

\author{
VIKTORIA HNATKOVSKA \\ AMARTYA LAHIRI \\ University of British Columbia \\ University of British Columbia \\ hnatkovs@interchange.ubc.ca \\ alahiri@interchange.ubc.ca \\ Carlos A.Vegh ${ }^{1}$ \\ University of Maryland and NBER \\ vegh@econ.bsos.umd.edu
}

Draft: September 2010 (VERY PRELIMINARY)

\footnotetext{
${ }^{1}$ We would like to thank seminar participants at the Federal Reserve Bank of New York, HEC Montreal, Colorado-Boulder, UBC, the 2007 annual meetings of Midwest Macro, CMSG Jr., and the SED for helpful comments. Lahiri would also like to thank SSHRC for research support.
} 


\begin{abstract}
Standard models in open economy macroeconomics predict that an expansionary (contractionary) monetary policy will lead to a currency depreciation (appreciation). Models that generate this prediction include the Dornbusch overshooting model, the flexible price model, the liquidity-effect models, as well as models based on the fiscal theory. The data however reveals an interesting twist to this prediction. We study a sample of 25 industrial and 49 developing countries and find that while the nominal exchange rate does indeed tend to appreciate in response to interest rate increases in developed countries, in develping countries the effect tends to be the opposite. In particular, in 84 percent of the developing countries in our sample, the nominal exchange rate depreciates in response to an increase in the interest rate. These findings represent a puzzle for standard models. To rationalize these empirical facts, we develop a model with two liquid assets (cash and demand-deposits) in which the central bank controls the interest rate on the liquid asset. The government finances its budget deficit with inflationary finance and firms must rely on bank credit to finance their working capital. The model generates opposing effects of interest rate changes on the exchange rate - a money demand effect, a fiscal effect and an output effect. We show that a calibrated version of the model rationalizes the opposing responses in developed and developing countries.
\end{abstract}

JEL Classification: F3, F4

Keywords: Interest rate policy, flexible exchange rates, currency depreciation 


\section{Introduction}

Standard models in open economy macroeconomics predict that an expansionary (contractionary) monetary policy will lead to a currency depreciation (appreciation). In Dornbusch's (1976) celebrated overshooting model, for example, an increase in the money supply results in a lower nominal interest rate and a more-than-proportional increase in the nominal exchange rate. ${ }^{1}$ The mechanism is simple enough: due to sticky prices, an increase in the nominal money supply is tantamount to an increase in the real money supply. Since output is taken as exogenous, this incipient excess supply of real money balances requires a fall in the nominal interest rate to equilibrate the money market. Given the interest parity condition, the nominal interest rate can only fall if the public expects an increase in the rate of appreciation of the domestic currency. This is only possible if the nominal exchange rate jumps above its long-run level and then falls over time. ${ }^{2}$

While the Dornbush-Obstfeld-Rogoff paradigm (or Mundell-Fleming in modern clothes) is, by far, the most widely used in monetary models of the open economy, four other types of models yield exactly the same prediction: (i) flexible prices model; (ii) liquidity-type models, (iii) models based on the fiscal theory of the price level, and (iv) models with more than one liquid asset. Specifically:

- While not always recognized, frictions are not needed to rationalize the idea of a negative relationship between nominal interest rates and the level of the exchange rate. Consider the simplest possible monetary model with flexible prices and monetary neutrality. A temporary increase in the level of the nominal money supply will lead, on impact, to a fall in the nominal interest rate and an increase in the nominal exchange rate (i.e., a depreciation of the currency). ${ }^{3}$ Intuitively, because the increase in the nominal money supply will be reversed in the future, the nominal exchange rises less than proportionately. A fall in the nominal interest rate is thus needed to equilibrate the money market.

- In liquidity-type models, an increase in the money supply also leads to a fall in the nominal

\footnotetext{
${ }^{1}$ Dornbusch's 1976 model is, of course, the traditional Mundell-Fleming model with rational expectations. With added microfoundations and other refinements - as reflected in Obstfeld and Rogoff's (1995) highly influential version - this model continues to be the workhorse of international finance well into the 21st century.

${ }^{2}$ It is important to note that we are characterizing the stance of monetary policy by looking at changes in the level of the money supply, as opposed to changes in the rate of change of the money supply. In the latter case, inflationary expectations will be affected and an expansionary monetary policy will be associated with a higher nominal interest rate.

${ }^{3}$ This result is easy to show using, for instance, the continuous-time version presented in Vegh (2010, Chapter 5). Of course, a permanent change in the nominal money supply would not have no effects on the nominal interest rate.
} 
interest rate because the increased money supply affects disproportionately some particular agents (say, financial firms). ${ }^{4}$ The nominal interest rate must fall for such agents to absorb the excess liquidity. In an open economy, the fall in the nominal interest rate will be associated with a currency depreciation.

- In open-economy models based on the fiscal theory of the price level (see, for example, Auernheimer (2008)), we can think of the nominal interest rate as the policy instrument. As long as the interest-rate elasticity of money demand is less than one (as is typically the case in practice), an increase in the nominal interest rate raises inflation tax revenues. These higher revenues imply that the government can afford to service a higher real stock of government debt, which requires a fall in the price level (i.e., the nominal exchange rate). Conversely, a reduction in the policy interest rate will lead to a currency depreciation.

- In models with imperfect substitution between two liquid assets, we can also think of the nominal interest rate on an interest-bearing liquid asset as a policy instrument. ${ }^{5}$ An increase in this policy interest rate leads to an increased demand for the liquid asset, which requires a fall in the nominal exchange rate.

There is thus overwhelming theoretical support for the proposition that expansionary monetary policy (i.e., a lower nominal interest rate) should lead to a currency depreciation and viceversa. But what does the empirical evidence say? Most of the empirical studies have looked at industrial countries and conclude that, indeed, this theoretical proposition holds true. The best-known study for the United States is Eichenbaum and Evans (1995) who conclude, using a VAR analysis, that a contractionary monetary policy in the United States leads to an appreciation of the dollar relative to all major currencies. In turn, Kim and Roubini (2000) use a structural VAR approach, which takes care of some identification problems that had plagued this literature up to this point, to look at non-US G-7 countries and reach the same conclusion.

Case closed? Not in our view. In fact,we will argue in this paper that, contrary to the case of industrial countries, in developing countries the currency depreciates in response to an increase in interest rates. We establish this stylized fact based on a sample of 25 industrial and 49 developing countries. We first ran individual VARs and conclude that, for industrial countries, the domestic currency appreciates in response to an increase in interest rates in 84 percent of the cases. In

\footnotetext{
${ }^{4}$ See, for example, Christiano and Eichenbaum (1995) and Grilli and Roubini (1996).

${ }^{5}$ See Calvo and Vegh (1995) and Lahiri and Vegh (2003).
} 
sharp contrast, for developing countries we show that the nominal exchange rate increases (i.e., the domestic currency depreciates) in response to higher interest rates in 80 percent of the cases. We also illustrate this finding by running panel VARs for industrial and developing countries separately and showing how, in response to an increase in the interest rate, the currency appreciates in industrial countries but depreciates in developing countries. We will refer to these contrasting findings in industrial versus developing countries as the "exchange rate response puzzle."

How can we solve the exchange rate response puzzle? We present a model with two liquid assets (cash and demand-deposits) in which the central bank controls the interest rate on the liquid asset. The government finances its budget deficit with inflationary finance and firms must rely on bank credit to finance their working capital. In this set-up, an increase in the policy-controlled interest rate has three key effects. First, the higher interest rate increases the interest rate on deposits, which therefore raises the demand for deposits. This money demand effect tends to appreciate the currency and thus captures the traditional channel in our set-up. Second, by increasing the government's debt service costs, the higher interest rate raises the required seigniorage revenue to finance government spending and, ceteris paribus, increases the inflation rate. The rise in inflation increases the opportunity cost of holding liquid assets and tends to depreciate the currency. We will refer to this channel as the fiscal effect. Third, the higher domestic interest rate raises the lending rate to firms and thereby reduces employment and output. The output contraction reduces net revenues for the government and hence, increases the required seigniorage revenue to finance the government budget. This output effect also tends to depreciate the currency.

The net effect of a higher policy-controlled interest rate on the nominal exchange rate will thus depend on the relative strength of the money demand, fiscal, and output effects. If the money demand effect dominates the other two, then higher interest rates will lead to an appreciation of the currency. Conversely, if the money demand effect is dominated by the other two, the currency will depreciate. Our way of solving the exchange rate response puzzle is to argue - and then show quantitatively - that the fiscal effect and the output effect will be typically larger in developing than in industrial countries. The fiscal effect is larger because, traditionally, developing countries have ran larger fiscal deficits and relied more on inflationary finance (see, for instance, Fischer, Sahay, and Vegh (2002)). The output effect is larger because firms in developing countries need to rely more on bank credit as they are mostly unable to raise funds by issuing commercial paper.

As a final step, we recalibrate our model to developing and developed countries. We show that the model-generated impulse responses of exchange rates reproduce the patterns estimated in the 
data. We interpret our results as providing a rationalization for the failure of standard empirical methods to detect any systematic relationship between interest rates and exchange rates in the data.

We should note at the outset that our paper is not concerned with the relationship between the nominal market interest rate and the rate of currency depreciation. There is a voluminous literature which attempts to document and/or explain this relationship. This literature is concerned with the failure of the uncovered interest parity (UIP) condition (the "forward premium anomaly"). In our model interest parity holds for internationally traded bonds. Hence, we do not shed any new light on the observed deviations from UIP. Instead, our main focus is on the effects of policy-induced changes in nominal interest rates on the level of the exchange rate.

The rest of the paper is organized as follows. The next section presents some empirical evidence from a number of developing and developed countries detailing the mixed results on the relationship between interest rates and the exchange rate. Section 3 presents the model while Section 4 discusses how the model is calibrated and solved. Section 5 presents our quantitative results using the calibrated model. Section 6 compares the country specific impulse responses from the model with the data. The last section concludes.

\section{Empirical motivation (incomplete)}

We start off by empirically documenting our motivating issue (the lack of a systematic relationship between interest rates and the exchange rate) through a look at the data. We study the relationship by estimating unrestricted vector autoregressions (VARs) on a country-by-country basis for a sample of ten countries. Our sample includes six developing countries - Brazil, Korea, Mexico, Thailand, Peru and Philippines - and four developed countries - Canada, Germany, Italy, and the United States.

For our sample we chose a representative mix of developed and developing countries. We focus on periods during which the exchange rate in these countries was floating, so the starting date varies from country to country. Here we report the empirical results from the subsample ending in 2001. ${ }^{6}$ We also investigated the evidence for the entire period ending in 2007. The results remained qualitatively unchanged for all countries except for Brazil and Thailand. We explore

\footnotetext{
${ }^{6}$ The sample periods are as follows: Brazil 1998:12 - 2001:03; Mexico 1995:01 - 2001:03; Peru 1992:01 - 2001:03; Korea 1997:07 - 2001:03; Thailand 1997:07 - 2001:03; and Phillipines 1983:01 - 2001:03. We chose four major developed countries as a control group. The sample period for developed countries is 1974:01 - 2001:03.
} 
these two countries and their changing responses in greater detail below in Section 7 . We chose to examine the periods 1997 - 2001 and 1997 - 2007 separately as there was a perceptible difference in monetary conditions between the two. During the period 1997-2001 the interest rate was used very actively by a number of central banks to defend against speculative attacks on their currencies. In contrast, the period 2001-2007 was one of relative tranquility in international currency markets. As a result interest rates were much less volatile during the latter phase relative to the first sub-sample.

We estimate country-specific four variable VARs using monthly data on nominal exchange rates (domestic currency units per U.S. dollar, period average), short term interest rate differentials between home and abroad (domestic minus U.S. Federal Funds rate), industrial production (index, 2000 base year) and government fiscal balance. ${ }^{7}$ We express the fiscal balance data in terms of U.S. currency and then normalize the resulting numbers across countries by expressing them in per capita terms. ${ }^{8}$ For the United States, the exchange rate is expressed in terms of dollar per yen while the interest rate differential is the U.S. minus the Japanese short term interest rate. Since monthly fiscal data for all countries in our sample is highly seasonal and volatile, we use the 11-month centered moving average instead. Our data is from the International Financial Statistics (IFS). ${ }^{9}$

We use the estimated VARs to calculate the impulse response of the exchange rate, industrial production, and the fiscal balance to an orthogonalized one standard deviation innovation in the interest rate differential between home and abroad for each country. Following Eichenbaum and Evans (1995) we compute the impulse responses using the following ordering: industrial production, interest rate differential, exchange rate, and fiscal balance. ${ }^{10}$

Figure 1 depicts the impulse response of the nominal exchange rate (with a one standard deviation significance band) to a one standard deviation orthogonalized innovation in the interest rate differential. The picture reveals mixed results. Within the set of developed countries, in Canada, Germany and Italy there is a significant appreciation of the currency in response to an increase in the interest rate differential. This is the well-known result of Eichenbaum and Evans (1995). For the developing group the effect is mostly the opposite. Except for Thailand, in all

\footnotetext{
${ }^{7}$ Whenever available, we use the interest payments data instead of the fiscal balance data in order to have more accurate correspondence with the model-generated series.

${ }^{8}$ We express the fiscal balance in this form in order to keep the measured fiscal balance in the data consistent with the way it is measured in the model that we present later.

${ }^{9}$ For the interest rate data, we use short term money market rates. For the U.S., the series used is the Federal Funds rate.

${ }^{10}$ The Akaike criterion was used to choose the lag length.
} 
countries a positive innovation in the interest rate differential between home and the United States induces a significant depreciation of the currency. Thailand, on the other hand, shows a significant appreciation of the currency in response to an interest rate innovation.

However, even for the developed countries the relationship between interest rates and exchange rates is not stable over time. Thus, for the U.S. we split the sample into two sub-periods - 1974:01 - 1990:05 and 1990:06 - 2001:03. Note that the first sub-period corresponds to the period analyzed in Eichenbaum and Evans (1995). As can be seen from the last row of Figure 1, the exchange rate effect of an interest rate innovation is different in the two sub-periods. For 1974:01-1990:05 we see the standard result - a positive innovation in the interest rate differential between the US and Japan causes a significant exchange rate appreciation. However, this relationship is reversed for the latter period in which the dollar depreciates relative to the yen in response to an innovation in the same interest rate differential. ${ }^{11}$

Our evidence is thus consistent with the lack of a systematic relationship between interest rates and the exchange rate in the data. As can be seen in Figure 1, this puzzle exists both on a cross-country basis as well as on a time series basis.

\section{The model}

Consider a representative household model of a small open economy that is perfectly integrated with the rest of the world in both goods and capital markets. The infinitely-lived household receives utility from consuming a (non-storable) good and disutility from supplying labor. The world price of the good in terms of foreign currency is fixed and normalized to unity. Free goods mobility across borders implies that the law of one price applies. The consumer can also trade freely in perfectly competitive world capital markets by buying and selling real bonds which are denominated in terms of the good and pay $r$ units of the good as interest at every point in time.

\subsection{Households}

Household's lifetime welfare is given by

$$
V=\mathbb{E}_{0} \sum_{t=0}^{\infty} \beta^{t} U\left(c_{t}, x_{t}\right),
$$

\footnotetext{
${ }^{11}$ We also estimated the VAR system for these countries for the entire sample ending in 2007:10. The results remained qualitatively unchanged for all countries except for Brazil and Thailand. We explore these two countries and their changing responses in greater detail below in Section 7.
} 
where $c$ denotes consumption, $x$ denotes labor supply, and $\beta(>0)$ is the exogenous and constant rate of time preference. We assume that the period utility function of the representative household is given by

$$
U(c, x)=\frac{1}{1-\sigma}\left(c-\zeta x^{\nu}\right)^{1-\sigma}, \quad \zeta>0, \quad \nu>1 .
$$

Here $\sigma$ is the intertemporal elasticity of substitution, $\nu-1$ is the inverse of the elasticity of labor supply with respect to the real wage. These preferences are well-known from the work of Greenwood, Hercowitz and Huffman (1988), which we will refer to as GHH. ${ }^{12}$

Households use cash, $H$, and nominal demand deposits, $D$, for reducing transactions costs. Specifically, the transactions costs technology is given by

$$
s_{t}=v\left(\frac{H_{t}}{P_{t}}\right)+\psi\left(\frac{D_{t}}{P_{t}}\right)
$$

where $P$ is the nominal price of goods in the economy, and $s$ denotes the non-negative transactions costs incurred by the consumer. Let $h(=H / P)$ denote cash and let $d(=D / P)$ denote interestbearing demand deposits in real terms. We assume that the transactions technology is strictly convex. In particular, the functions $v(h)$ and $\psi(d)$, defined for $h \in[0, \bar{h}], \bar{h}>0$, and $d \in[0, \bar{d}]$, $\bar{d}>0$, respectively, satisfy the following properties:

$$
\begin{aligned}
& v \geq 0, \quad v^{\prime} \leq 0, \quad v^{\prime \prime}>0, \quad v^{\prime}(\bar{h})=v(\bar{h})=0 \\
& \psi \geq 0, \quad \psi^{\prime} \leq 0, \quad \psi^{\prime \prime}>0, \quad \psi^{\prime}(\bar{d})=\psi(\bar{d})=0 .
\end{aligned}
$$

Thus, additional cash and demand deposits lower transactions costs but at a decreasing rate. The assumption that $v^{\prime}(\bar{h})=\psi^{\prime}(\bar{d})=0$ ensures that the consumer can be satiated with real money balances.

In addition to the two liquid assets, households also hold a real internationally-traded bond, $b$, and physical capital, $k$, which they can rent out to firms. The households flow budget constraint in nominal terms is

$$
\begin{aligned}
& P_{t} b_{t+1}+D_{t}+H_{t}+P_{t}\left(c_{t}+I_{t}+s_{t}+\kappa_{t}\right) \\
= & P_{t}\left(R b_{t}+w_{t} x_{t}+\rho_{t} k_{t-1}+\tau_{t}+\Omega_{t}^{f}+\Omega_{t}^{b}\right)+\left(1+i_{t}^{d}\right) D_{t-1}+H_{t-1} .
\end{aligned}
$$

\footnotetext{
${ }^{12}$ These preferences have been widely used in the real business cycle literature as they provide a better description of consumption and the trade balance for small open economies than alternative specifications (see, for instance, Correia, Neves, and Rebelo (1995)). As will become clear below, the key analytical simplification introduced by GHH preferences is that there is no wealth effect on labor supply.
} 
Foreign bonds are denominated in terms of the good and pay the gross interest factor $R(=1+r)$, which is constant over time. $i_{t}^{d}$ denotes the deposit rate contracted in period $t-1$ and paid in period $t . \quad w$ and $\rho$ denote the wage and rental rates. $\tau$ denotes lump-sum transfers received from the government. $\Omega^{f}$ and $\Omega^{b}$ represent dividends from firms and banks respectively. $\kappa$ denotes capital adjustment costs

$$
\kappa_{t}=\kappa\left(I_{t}, k_{t-1}\right), \quad \kappa_{I}>0, \kappa_{I I}>0
$$

i.e., adjustment costs are convex in investment. Lastly,

$$
I_{t}=k_{t}-(1-\delta) k_{t-1}
$$

In real terms the flow budget constraint facing the representative household is thus given by

$$
\begin{aligned}
& b_{t+1}+h_{t}+d_{t}+c_{t}+I_{t}+s_{t}+\kappa_{t} \\
= & R b_{t}+w_{t} x_{t}+\rho_{t} k_{t-1}+\frac{h_{t-1}}{1+\pi_{t}}+\left(\frac{1+i_{t}^{d}}{1+\pi_{t}}\right) d_{t-1}+\Omega_{t}^{f}+\Omega_{t}^{b},
\end{aligned}
$$

where $\Omega^{f}$ and $\Omega^{b}$ denote dividends received by households from firms and banks, respectively. $1+\pi_{t}=\frac{P_{t}}{P_{t-1}}$ denotes the gross rate of inflation between periods $t-1$ and $t . \quad$ It is useful to note that the uncovered interest parity condition dictates that expected returns from investing in domestic nominal bonds and international real bonds must be equalized. Hence, recalling that $P_{t+1} / P_{t}=1+\pi_{t+1}$,

$$
1+i_{t+1}=R \mathbb{E}_{t}\left(1+\pi_{t+1}\right)
$$

Households maximize their lifetime welfare equation (1) subject to equations (2), (3), (4) and $(5)$.

\subsection{Firms}

The representative firm in this economy produces the perishable good using a constant returns to scale technology over capital and labor

$$
y_{t}=F\left(k_{t-1}, A_{t} l_{t}\right)=A_{t} k_{t-1}^{\alpha} l_{t}^{1-\alpha}
$$

with $\alpha>0$, and $A_{t}$ denoting the current state of productivity which is stochastic. $l$ is labor demand. At the beginning of the period, firms observe shocks for the period and then make production plans. They rent capital and labor. However, a fraction $\phi$ of the total wage bill needs to be paid upfront to workers. Since output is only realized at the end of the period, firms finance 
this payment through loans from banks. The loan amount along with the interest is paid back to banks next period. ${ }^{13}$ Formally, this constraint is given by

$$
N_{t}=\phi P_{t} w_{t} l_{t}, \quad \phi>0
$$

where $N$ denotes the nominal value of bank loans. The assumption that firms must use bank credit to pay the wage bill is needed to generate a demand for bank loans.

The firm's flow constraint in nominal terms is given by

$$
P_{t} b_{t+1}^{f}-N_{t}=P_{t}\left(R b_{t}^{f}+y_{t}-w_{t} l_{t}-\rho_{t} k_{t-1}-\Omega_{t}^{f}\right)-\left(1+i_{t}^{l}\right) N_{t-1}
$$

where $i^{l}$ is the lending rate charged by bank for their loans and $\Omega^{f}$ denotes dividends paid out by the firms to their shareholders. $b^{f}$ denotes foreign bonds held by firms which pay the going world interest factor $R$. In real terms the flow constraint reduces to

$$
b_{t+1}^{f}-n_{t}=R b_{t}^{f}-\left(\frac{1+i_{t}^{l}}{1+\pi_{t}}\right) n_{t-1}+y_{t}-w_{t} l_{t}-\rho_{t} k_{t-1}-\Omega_{t}^{f} .
$$

Define

$$
a_{t+1}^{f} \equiv b_{t+1}^{f}-\frac{\left(1+i_{t+1}^{l}\right)}{R\left(1+\pi_{t+1}\right)} n_{t} .
$$

Substituting this expression together with the credit-in-advance constraint into the firm's flow constraint in real terms gives

$$
a_{t+1}^{f}+\Omega_{t}^{f}=R a_{t}^{f}+y_{t}-\rho_{t} k_{t-1}-w_{t} l_{t}\left[1+\phi\left\{\frac{1+i_{t+1}^{l}-R\left(1+\pi_{t+1}\right)}{R\left(1+\pi_{t+1}\right)}\right\}\right] .
$$

Note that $\phi\left\{\frac{1+i_{t+1}^{l}-R\left(1+\pi_{t+1}\right)}{R\left(1+\pi_{t+1}\right)}\right\} w_{t} l_{t}=\left\{\frac{1+i_{t+1}^{l}-R\left(1+\pi_{t+1}\right)}{R\left(1+\pi_{t+1}\right)}\right\} n_{t}$ is the additional resource cost that is incurred by firms due to the credit-in-advance constraint. ${ }^{14}$

The firm chooses a path of $l$ and $k$ to maximize the present discounted value of dividends subject to equations (6), (7) and (8). Given that households own the firms, this formulation is equivalent to the firm using the household's stochastic discount factor to optimize. The first order conditions for this problem are given by two usual conditions and an Euler equation which is identical to the

\footnotetext{
${ }^{13}$ Alternatively, we could assume that bank credit is an input in the production function, in which case the derived demand for credit would be interest rate elastic. This would considerably complicate the model without adding any additional insights.

${ }^{14}$ We should note that the credit-in-advance constraint given by equation (7) holds as an equality only along paths where the lending spread $1+i^{l}-R(1+\pi)$ is strictly positive. We will assume that if the lending spread is zero, this constraint also holds with equality.
} 
household's Euler equation. The two usual conditions are standard - the firm equates the marginal product of the factor to its marginal cost. In the case of labor the cost includes the cost of credit. This is proportional to the difference between the nominal lending rate and the nominal interest rate.

\subsection{Banks}

The banking sector is assumed to be perfectly competitive. The representative bank holds foreign real debt, $d^{b}$, accepts deposits from consumers and lends to both firms, $N$, and the government in the form of domestic government bonds, $Z{ }^{15}$ It also holds required cash reserves, $\theta D$, where $\theta>0$ is the reserve-requirement ratio imposed on the representative bank by the central bank. Banks face a cost $q$ (in real terms) of managing their portfolio of foreign assets. Moreover, we assume that banks also face a constant proportional cost $\phi^{n}$ per unit of loans to firms. This is intended to capture the fact that domestic loans to private firms are potentially special as banks need to spend additional resources in monitoring loans to private firms. ${ }^{16}$ The nominal flow constraint for the bank is

$$
\begin{aligned}
N_{t}+Z_{t}-(1-\theta) D_{t}+P_{t} q_{t}-P_{t} d_{t+1}^{b}= & \left(1+i_{t}^{l}-\phi^{n}\right) N_{t-1}+\left(1+i_{t}^{g}\right) Z_{t-1} \\
& -\left(1+i_{t}^{d}\right) D_{t-1}+\theta D_{t-1}-P_{t} R d_{t}^{b}-P_{t} \Omega_{t}^{b},
\end{aligned}
$$

where $i^{g}$ is the interest rate on government bonds. We assume that banking costs are a convex function of the foreign debt held by the bank:

$$
q_{t}=q\left(d_{t+1}^{b}\right), \quad q^{\prime}>0, q^{\prime \prime}>0
$$

where $q^{\prime}$ denotes the derivative of the function $q$ with respect to its argument, while $q^{\prime \prime}$ denotes the second derivative. The costly banking assumption is needed to break the interest parity condition between domestic and foreign bonds. Throughout the paper we assume that the banking cost

\footnotetext{
${ }^{15}$ Commercial bank lending to governments is particularly common in developing countries. Government debt is held not only as compulsory (and remunerated) reserve requirements but also voluntarily due to the lack of profitable investment opportunities in crisis-prone countries. This phenomenon was so pervasive in some Latin American countries during the 1980's that Rodriguez (1991) aptly refers to such governments as "borrowers of first resort". For evidence, see Rodriguez (1991) and Druck and Garibaldi (2000).

${ }^{16}$ We should note that this cost $\phi^{n}$ is needed solely for numerical reasons since, as will become clear below, it gives us a bigger range of policy-controlled interest rates to experiment with. Qualitatively, all our results would go through with $\phi^{n}=0$.
} 
technology is given by the quadratic function:

$$
q_{t}=\frac{\gamma}{2}\left(d_{t+1}^{b}\right)^{2}
$$

where $\gamma>0$ is a constant parameter. ${ }^{17}$

Deflating the nominal flow constraint by the price level gives the bank's flow constraint in real terms:

$$
\Omega_{t}^{b}=\left[\frac{R\left(1+\pi_{t}\right)-1}{1+\pi_{t}}\right]\left[(1-\theta) d_{t-1}-n_{t-1}-z_{t-1}\right]+\frac{i_{t}^{l}-\phi^{n}}{1+\pi_{t}} n_{t-1}+\frac{i_{t}^{g}}{1+\pi_{t}} z_{t-1}-\frac{i_{t}^{d}}{1+\pi_{t}} d_{t-1}-q_{t},
$$

where we have used the bank's balance sheet identity: $P_{t} d_{t+1}^{b}=N_{t}+Z_{t}-(1-\theta) D_{t}$. Note that this is equivalent to setting the bank's net worth to zero at all times. Also, the quadratic specification for banking costs along with the zero net worth assumption implies that these banking costs can also be reinterpreted as a cost of managing the portfolio of net domestic assets since $d_{t+1}^{b}=\frac{N_{t}+Z_{t}-(1-\theta) D_{t}}{P_{t}}$.

The representative bank chooses sequences of $N, Z$, and $D$ to maximize the present discounted value of profits subject to equations (9) taking as given the paths for interest rates $i^{l}, i^{d}, i^{g}, i$, and the value of $\theta$ and $\phi^{n}$. We assume that the bank uses the household's stochastic discount factor to value its profits. Note that $i_{t+1}^{g}, i_{t+1}^{l}$ and $i_{t+1}^{d}$ are all part of the information set of the household at time $t$.

The bank optimality conditions imply that we must have

$$
\begin{aligned}
& i_{t+1}^{l}=i_{t+1}^{g}+\phi^{n} \\
& i_{t+1}^{d}=(1-\theta) i_{t+1}^{g} .
\end{aligned}
$$

These conditions are intuitive. Loans to firms and loans to the government are perfect substitutes from the perspective of commercial banks up to the constant extra marginal cost $\phi^{n}$ of monitoring loans to private firms. Hence, equation (12) says that the interest rate charged by banks on private loans should equal the rate on loans to the government plus $\phi^{n}$. For every unit of deposits held the representative bank has to pay $i^{d}$ as interest. The bank can earn $i^{g}$ by lending out the deposit. However, it has to retain a fraction $\theta$ of deposits as required reserves. Hence, equation (13) shows that at an optimum the deposit rate must equal the interest on government bonds net of the resource cost of holding required reserves. We should note that the parameter $\phi^{n}$ plays no role

\footnotetext{
${ }^{17}$ Similar treatment of banking costs of managing assets and liabilities can be found in Diaz-Gimenez et al (1992) and Edwards and Végh (1997). This approach to breaking the interest parity condition is similar in spirit to Calvo and Végh (1995).
} 
in the theoretical results that we derive below. Hence, in our main propositions we set $\phi^{n}=0$. This parameter is useful in the quantitative sections later where it allows us to calibrate some key interest rate spreads.

It is instructive to note that as the marginal banking costs becomes larger the bank will choose to lower its holdings of foreign assets. This can be checked from the bank first order conditions; all of them imply that $\lim _{\gamma \rightarrow \infty} d_{t+1}^{b}=0$. Hence, in the limit as banking costs becomes prohibitively large, the bank will choose to economize by shifting to a closed banking sector with no external assets or liabilities.

\subsection{Government}

The government issues high powered money, $M$, and domestic bonds, $Z$, makes lump-sum transfers, $\tau$, to the public, and sets the reserve requirement ratio, $\theta$, on deposits. Domestic bonds are interest bearing and pay $i^{g}$ per unit. Since we are focusing on flexible exchange rates, we assume with no loss of generality that the central bank's holdings of international reserves are zero. We assume that the government's transfers to the private sector are fixed exogenously at $\bar{\tau}$ for all $t$. Hence, the consolidated government's nominal flow constraint is

$$
P_{t} \bar{\tau}+\left(1+i_{t}^{g}\right) Z_{t-1}=M_{t}-M_{t-1}+Z_{t}
$$

As indicated by the left-hand-side of this expression, total expenditures consist of lump-sum transfers, debt redemption and debt service. These expenditures may be financed by issuing either high powered money or bonds. In real terms the government's flow constraint reduces to

$$
\bar{\tau}+\frac{1+i_{t}^{g}}{1+\pi_{t}} z_{t-1}=m_{t}+z_{t}-\frac{1}{1+\pi_{t}} m_{t-1}
$$

Lastly, the rate of growth of the nominal money supply is given by:

$$
\frac{M_{t+1}}{M_{t}}=1+\mu_{t+1}, \quad M_{0} \text { given }
$$

It is worth noting that from the central bank's balance sheet the money base in the economy is given by

$$
M_{t}=H_{t}+\theta D_{t}
$$

Hence, $M$ can also be interpreted as the level of nominal domestic credit in the economy.

The consolidated government (both the fiscal and monetary authorities) has three policy instruments: (a) monetary policy which entails setting the rate of growth of nominal money supply; (b) 
interest rate policy which involves setting $i^{g}$ (or alternatively, setting the composition of $m$ and $z$ and letting $i^{g}$ be market determined); and (c) the level of lump sum transfers to the private sector $\tau$. Given that lump-sum transfers are exogenously-given, only one of the other two instruments can be chosen freely while the second gets determined through the government's flow constraint (equation (14)). Since the focus of this paper is on the effects of interest rate policy, we shall assume throughout that $i^{g}$ is an actively chosen policy instrument. This implies that the rate of money growth $\mu$ adjusts endogenously so that equation (14) is satisfied.

\subsection{Resource constraint}

By combining the flow constraints for the consumer, the firm, the bank, and the government (equations (5), (8), (11) and (14)) and using equations (6) and (7), we get the economy's flow resource constraint:

$$
a_{t+1}=R a_{t}+y_{t}-c_{t}-I_{t}-\kappa_{t}-s_{t}-q_{t},
$$

where $a=b+b^{f}-d^{b}$. Note that the right hand side of equation (16) is simply the current account.

\subsection{Equilibrium relations}

We start by defining an equilibrium for this model economy. The three exogenous variables in the economy are the productivity process $A$ and the two policy variables $\bar{\tau}$ and $i^{g}$. We denote the entire state history of the economy till date $t$ by $s^{t}=\left(s_{0}, s_{1}, s_{2}, \ldots, s_{t}\right)$. An equilibrium for this economy is defined as:

Given a sequence of realizations $A\left(s^{t}\right), i^{g}\left(s^{t}\right), r$ and $\bar{\tau}$, an equilibrium is a sequence of state contingent allocations $\left\{c\left(s^{t}\right), x\left(s^{t}\right), l\left(s^{t}\right), h\left(s^{t}\right), d\left(s^{t}\right), k\left(s^{t}\right), b\left(s^{t}\right), b^{f}\left(s^{t}\right), d^{b}\left(s^{t}\right), n\left(s^{t}\right), z\left(s^{t}\right)\right\}$ and prices $\left\{P\left(s^{t}\right), \pi\left(s^{t}\right), i\left(s^{t}\right), i^{d}\left(s^{t}\right), i^{l}\left(s^{t}\right), w\left(s^{t}\right), \rho\left(s^{t}\right)\right\}$ such that (a) at the prices the allocations solve the problems faced by households, firms and banks; (b) factor markets clear; and (c) the government budget constraint (equation (14)) is satisfied.

Combining the government flow constraint with the central and commercial bank balance sheets yields the combined government flow constraint:

$$
\bar{\tau}=h_{t}-\left(\frac{1}{1+\pi_{t}}\right) h_{t-1}+\theta\left(d_{t}-\frac{d_{t-1}}{1+\pi_{t}}\right)+z_{t}-\left(\frac{1+i_{t}^{g}}{1+\pi_{t}}\right) z_{t-1}
$$

For future reference, the nominal interest rate in this economy is given by the standard no arbitrage condition between a one-period nominal bond bought at time $t$ which pays $i_{t+1}$ as interest 
in domestic currency at $t+1$ and an international real bond which pays $r$ as interest in terms of the good:

$$
1+i_{t+1}=R \mathbb{E}_{t}\left(1+\pi_{t+1}\right) .
$$

It is useful at this stage to clarify the process of nominal exchange rate determination in this model. Let $m=M / E$ be real money while nominal money is denoted by $M=H+\theta D$. Since $h$ and $d$ are functions of $i$ and $i-i^{d}$ respectively, the money market equilibrium condition can be written implicitly as $h+\theta d=L\left(i, i^{g}\right)$ where $L$ denotes the implicit aggregate demand for cash and deposits. Note that in writing the implicit $L$ function we have used the fact $i^{d}$ is linked one-for-one with $i^{g}$. At any date $t, M_{t}$ is known while its growth rate $\mu_{t+1}$ is endogenous. Money market equilibrium then dictates that at date $t$ the nominal exchange rate is given by

$$
E_{t}=\frac{M_{t}}{L\left(i_{t}, i_{t}^{g}\right)}
$$

For any given policy rate $i_{t}^{g}$, the inflation rate $\pi_{t}$ (and hence the nominal interest rate $i_{t}$ ) is determined from the government budget constraint (17). From equation (19), knowledge of $i_{t}^{g}$ and $i_{t}$ are sufficient to determine the nominal exchange rate $E_{t}$ at that date for a given $M_{t}$. Note that the rate of nominal money growth $\mu$ between dates $t$ and $t+1$ also gets determined at date from equation (14). Hence, $M_{t+1}$ gets determined at date $t$.

\subsection{The tradeoffs}

The model laid out above has the three key margins that we set out to include. To see this note that a rise in the policy controlled interest rate $i^{g}$ has two direct effects. First, it raises both the lending rate rate $i^{l}$ and the deposit rate $i^{d}$. Ceteris paribus, this raises the lending spread $i^{l}-i$ and reduces the deposit spread $i-i^{d}$. The effect on the lending spread reduces the demand for loans and thereby also reduces output. This is the "output" effect wherein higher interest rates have a recessionary effect by raising the cost of financing working capital requirements. The lower deposit spread, on the other hand, raises the demand for deposits. This increases the demand for money the "money demand" effect.

The fiscal effect is more complicated. Notice that an increase in $i^{g}$ directly increases the cost of servicing government bonds $Z$ which increases the fscal burden. However, there are two other indirect ways in which changes in the policy controlled rate impacts the fiscal balance of the government. First, since a higher $i^{g}$ lowers the amount of private loans $N$, for a given level of demand deposits commercial banks make more loans to the public sector, i.e., $Z$ rises. This reduces 
the reliance on inflationary finance today but raises the future fiscal burden through a higher base level of debt. This effect arises as a consequence of the "output" effect. On the other side, a higher $i^{d}$ raises demand deposits with commercial banks. For a given level of private loans, this reduces the reliance on inflationary finance today to finance government spending. This effect arises due to the "money demand" effect.

The effect of an interest rate increase on the equilibrium nominal exchange rate then depends on the net effect of these often offsetting effects. Notice that the exchange rate depends not just on monetary conditions but also on the real side of the economy as well as the state of public finances. They are all fundamental determinants of the exchange rate. Interest rate changes impact these fundamentals in often opposing ways. This is likely to make its end effect on the exchange rate non-linear and possibly non-monotonic. We explore these possibilities quantitatively below.

\section{Calibration}

Policy experiments performed in the next section intend to demonstrate the central result of the paper: the relationship between interest rates and exchange rates may be non-monotonic. Towards this end we calibrate a discrete time version of the model developed above and assess its quantitative relevance for understanding the relationship between interest rates and the exchange rate. In this section we calibrate the parameters of the model as well as the processes for productivity, interest rate, and fiscal policy shocks. For our benchmark calibration we use the data for Argentina during 1983-2002. The model calibration is such that one period in the model corresponds to one quarter.

\subsection{Functional forms and parameters}

We assume that the capital adjustment cost technology is given by

$$
\kappa\left(I_{t}, k_{t-1}\right)=\frac{\xi}{2} k_{t-1}\left(\frac{I_{t}-\delta k_{t-1}}{k_{t-1}}\right)^{2}, \quad \xi>0,
$$

with $\xi$ being the level parameter.

Following Rebelo and Vegh (1995), we assume that the transactions costs functions $v($.$) and$ $\psi($.$) have quadratic forms given by$

$$
s_{\varkappa}\left(\varkappa^{2}-\varkappa+\frac{1}{4}\right),
$$

where $\varkappa$ represents cash or demand deposits, $\varkappa=\{h, d\}$ and $s_{\varkappa}$ are the level parameters. This formulation implies that the demand for money components are finite and that transaction costs 
are zero when the nominal interest rate is zero. ${ }^{18}$

The transaction technology for the banks is given by a quadratic function

$$
q_{t}=\frac{\gamma}{2}\left(d_{t+1}^{b}\right)^{2}
$$

where $d_{t+1}^{b}=\frac{N_{t}+Z_{t}-(1-\theta) D_{t}}{P_{t}}$.

Most of our parameter values are borrowed from Neumeyer and Perri (2005). In particular, we set the coefficient of relative risk aversion, $\sigma$, to 5 , while the curvature of the labor, $v$, is set to 1.6, which is within the range of values used in the literature. ${ }^{19}$ This implies the elasticity of labor demand with respect to real wage, $\frac{1}{v-1}$, equal to 1.67 , consistent with the estimates for the U.S. Labor weight parameter $\zeta$ in the utility function is chosen to match the average working time of $1 / 5$ of total time and is set to 2.48. Subjective discount factor, $\beta$, is set to 0.97 , as in Uribe and Yue (2006).

Capital income share, $\alpha$, is chosen to be equal to 0.38 , while a depreciation rate for capital, $\delta$, of $4.4 \%$ per quarter. We calibrate the share of wage bill paid in advance, $\phi$, to be equal to 0.26 , which is chosen to match the ratio of domestic private business sector credit to GDP in Argentina over our sample period. The number for private credit to GDP in Argentina is borrowed from the Financial Structure Dataset assembled by Beck, Demirgüç-Kunt and Levine (2000) and is equal to 0.21. The share of business sector credit in the total private sector credit is calculated using activity based financing reports from the Central Bank of Argentina, and is equal to $78 \%$ over our sample period. Capital adjustment costs parameter $\xi$ is calibrated to replicate the volatility of investment relative to the volatility of output in Argentina. Parameter $\theta$ determines the reserve requirement ratio in the model and is set to match its value of 0.4 in Argentina.

The level coefficients in the transactions costs technology, $s_{h}$ and $s_{d}$, are set to 10 and 5 , respectively, in order to match seignorage revenues in Argentina equal to 7\% of GDP. This number is taken from Kiguel (1989) and was used by Rebelo and Vegh (1995) to calibrate the transaction costs technology. We follow their strategy in our calibration exercise. Parameters $s_{h}$ and $s_{d}$ also allow us to pin down the initial values of money demand elasticities, $\eta_{h}$ and $\eta_{d}$, such that Condition 1 in Section ?? is satisfied. The proportional cost parameter $\phi^{n}$ in the banking sector' problem is chosen to match the average spread of nominal lending rate over money market rate equal $10 \%$ in

\footnotetext{
${ }^{18}$ Notice as well that condition 2 is met.

${ }^{19}$ For example, Mendoza (1991) uses $v$ equal to 1.455 for Canada, while Correia, et.al (1995) set $v$ to 1.7 for Portugal.
} 
Argentina over our sample period. Lastly, we pick $\gamma$ to match the economy-wide steady state bond holdings. Table 1 summarizes parameter values under our benchmark parametrization. ${ }^{20}$

\subsection{Calibration of the shock processes}

There are two sources of uncertainty in our benchmark model: exogenous productivity realizations, $A$, and the policy-controlled interest rate realizations, $i^{g}$. We now describe how we calibrate the total factor productivity (TFP) and the process for interest rates. We will use a "hat" over a variable to denote the deviation of that variable from its balanced growth path.

Following Neumeyer and Perri (2005) we assume that productivity, $\hat{A}_{t}$, in Argentina is an independent $\mathrm{AR}(1)$ process with autoregressive coefficient, $\rho_{\mathrm{A}}$, equal to 0.95 . The innovations, $\varepsilon^{\mathrm{A}}$, to this process are assumed to be independent and identically normally distributed with the standard deviation, $\sigma\left(\varepsilon^{\mathrm{A}}\right)$, equal to $0.0195 .^{21}$

To calibrate the process for the policy-controlled interest rate $i^{g}$, we use data on the money market rate in Argentina during 1992:2-2002:3. During this period the average level of $i^{g}$ was 13\%. We obtain $\hat{\imath}^{g}$ as a differential of Argentinean money market rate from the U.S. Federal Funds rate, and then estimate the first-order autoregressive process for $\hat{\imath}^{g}$ as

$$
\hat{\imath}_{t}^{g}=\rho_{g} \hat{\imath}_{t-1}^{g}+\varepsilon_{t}^{g}
$$

where $\varepsilon_{t}^{g}$ are i.i.d. normal innovations. The ordinary least squares (OLS) estimation of this equation gives $\rho_{g}=0.97$, and $\sigma\left(\varepsilon^{g}\right)=0.0353 .{ }^{22}$

To simplify the analytics of the model, up to now we have assumed that the lump-sum transfers paid by the government to the private sector, $\tau$, are fixed at $\bar{\tau}$. We measure $\bar{\tau}$ as the average (seasonally-adjusted) ratio of government consumption to GDP over our sample period, which gives $\bar{\tau}=13 \% .^{23}$

\footnotetext{
${ }^{20}$ For all the experiments reported below we checked to ensure that the implied inflation tax revenues are on the upward sloping portion of the Laffer-curve.

${ }^{21}$ This process is commonly used to describe total factor productivity in the U.S. In the absence of quarterly data on Argentinean employment, we rely on it to calibrate the dynamics of $\hat{A}_{t}$, as in Neumeyer and Perri (2005).

${ }^{22}$ Measuring $\hat{\imath}^{g}$ as a deviation of the money market rate from world interest rate proxied by U.S. Federal Funds rate is consistent with the VAR specification reported in Section 2. Moreover, it also provides a detrend of the interest rate data.

${ }^{23}$ As part of a sensitivity analysis we relaxed the assumption of a fixed $\tau$ and evaluated the model's implications when the process for fiscal spending is stochastic. We found that the exchange rate response to fiscal shocks are monotonic both in levels and rates.
} 
Once the shock processes and other parameter values are set, we solve the model using the perturbation method (Judd (1998), Schmitt-Grohe and Uribe (2004)). In particular, we take the second-order approximations of the model equilibrium conditions around the non-stochastic steady state, and then solve the resulting system of equations following the procedure described in SchmittGrohe and Uribe (2004). ${ }^{24}$

\section{Results}

We analyze the equilibrium properties of the model by conducting two experiments. First, we discuss how the variables in the model respond to temporary interest rate shocks of different magnitudes; and second, we compare the model responses to same sized interest rate shocks, but for different steady state levels of the interest rate.

\subsection{Temporary shocks around different steady state $i^{g}$ 's}

We now study the dynamics of the model around its non-stochastic steady state. First, we look at the impulse responses of the exchange rate and the rate of currency depreciation to a positive one standard deviation innovation to the policy-controlled interest rate $i^{g}$. We conduct this experiment for different steady state levels of $i^{g}$. The results of this exercise are presented in Figure 6.

For the benchmark parameterization with low steady state interest rates, a temporary increase in $i^{g}$ tends to appreciate the currency. Under high steady state interest rates, on the other hand, a temporary increase in $i^{g}$ has the reverse effect: both the level and the rate of currency depreciation increase. This comovement between the level and the rate of the exchange rate breaks down for intermediate levels of the steady state interest rate. Here a positive one standard deviation shock to $i^{g}$ will generate an appreciation in the nominal exchange rate, accompanied by an increase in the rate of depreciation. Consequently, the market interest rate also rises in this range. These results show that interest rates (both policy-controlled and market determined) and exchange rates can be positively or negatively related. Hence, if one were to conduct a similar exercise for a cross-section of countries with different initial levels of interest rates no systematic relationship between the two variables need necessarily arise.

\footnotetext{
${ }^{24}$ In our economy, international bonds may follow a unit root process. To account for this potential non-stationarity, we impose a small quadratic bond holding cost, $\Phi\left(a_{t}\right)=\frac{\vartheta}{2} y_{t}\left(\frac{a_{t}}{y_{t}}-\bar{a}\right)^{2}$, where $\bar{a}$ denotes the steady state ratio of bond holdings to GDP, and $\vartheta$ is a level parameter. This does not alter the model dynamics substantially, and therefore when discussing the results, we focus on the case with no bond holding costs.
} 


\subsection{Different sized shocks to steady state $i^{g}$}

Next, we study the impulse responses of interest rates and exchange rates to innovations in $i^{g}$ of different sizes. We analyze these responses around an invariant steady state $i^{g}$. We calibrate the steady state $i^{g}$ to the average money market rate in Argentina over 1992:2-2002:3, equal to 13\%. The results are presented in Figure 7.

It is easy to see that increases in interest rates up to 3 standard deviations cause the domestic currency to appreciate. However, more aggressive rises in $i^{g}$ would lead to currency depreciation. The rate of currency depreciation and the nominal interest rate always increase in response to interest rate shocks, independent of the magnitude of the shock. The reason is that for relatively high levels of steady state $i^{g}$ (13\% in our case), the interest burden of government debt is so high that it requires large seigniorage revenues to maintain the government budget. Therefore, the steady state inflation rate and the rate of currency depreciation are also high. Any further increase in $i^{g}$ raises the interest rate burden, thereby increasing the inflation rate some more. The money demand, on the other hand, continues to exhibit non-monotonicity in response to changes in $i^{g}$. In particular, at $i^{g}=13 \%$, the elasticity of demand for deposits is sufficiently high, while the cash elasticity is sufficiently low to generate a net increase in money demand for small innovations to $i^{g}$. This positive "money demand" effect will appreciate the currency. However, when innovations to $i^{g}$ become large, the "money demand" effect turns negative. As a result, the domestic currency depreciates. These findings highlight that the non-monotonicity in the relation between interest rates and exchange rates exists on the time-series basis as well.

In summary, we have shown that the relationship between interest rates and exchange rates is non-monotonic along three dimensions: First, the relationship is non-monotonic in the steady state; second, controlling for the steady state, the relationship is non-monotonic in the size of the interest rate changes. Lastly, controlling for the size of the innovations, the relationship is non-monotonic along the cross-sectional dimension.

\section{$6 \quad$ Matching country impulse responses}

This section describes the final test of our model. Consider again the empirical impulse responses presented at the beginning of the paper. We used those impulse responses to illustrate that it is hard to find any systematic relationship between interest rates and exchange rates in the data. For instance, we showed that for Thailand, a positive innovations to the interest rate differential 
induced a significant exchange rate appreciation. Korea, on the other hand, exhibited a depreciated exchange rate in response to an interest rate innovation. Finally, Brazil's exchange rate has shown no significant reaction to a change in interest rate differential. The objective of this section is to rationalize these opposite dynamics in the context of our model. For this purpose, we re-calibrate our model for Thailand, Korea and Brazil, and derive their corresponding theoretical impulse responses to interest rate innovations. We conduct this exercise for the two periods over which our chosen economies had flexible exchange rate regime: 1997-2001 which corresponds to a period of active interest rate defence in these economies; and the complete sample period of 1997-2007. We show that our model can qualitatively match the data for both periods.

The choice of the periods were dictated by two motivations. The first sub-period (1997-2001) was characterized by a number of currency crisis episodes in emerging countries. During this period the interest rate instrument was used very actively by these countries as a weapon to fight attacks on domestic currencies. The period from 2001 onward, on the other hand, has been one of relative tranquility. As a result the use of the interest rate instrument has been more active. Thus, during the period 1997-2001 the mean interest rate is about 340 basis points higher and the standard deviation of the interest rates is 40 percent higher relative to the full sample (1997-2007). Second, after 2001 there was a big and prolonged change in the US monetary policy with the Federal Funds rate dropping sharply in response to a developing recession. As a result, during the period 1997-2001 the mean level of the Federal Funds rate was about 170 basis points higher, while the standard deviation was 70 percent lower relative to the entire period of 1997-2007. Given that a key exogenous driver in the model is the spread between the policy controlled domestic interest rate and the exogenous world interest rate, both facts outlined above suggest that the properties of this spread may have changed significantly after 2001. Moreover, our counterfactual policy experiments above showed that the properties of the interest rate process are key components of potential nonmonotonicities in the exchange rate response to interest rate innovations. Hence, studying the two periods separately appears to be a natural test of the model.

\subsection{Active interest rate period}

We keep all of the preference parameters and most of the technology and money parameters unchanged. We only recalibrate two key parameters: the share of wage-in-advance, $\phi$, to match the ratio of domestic business credit to GDP; and the reserve requirement ratio, $\theta$, in our three 
economies. $^{25}$ In calibrating all parameters and shock processes we use the time periods considered in the construction of the empirical impulse responses: 1997:q3 - 2001:q1 for Thailand and Korea; and 1998:q4 - 2001:q1 for Brazil. ${ }^{26}$

As before, we measure $i_{t}^{g}$ as the money market rate in a given country. During the sample periods the average level of $i^{g}$ was $7 \%$ for Thailand, $9 \%$ for Korea, and $23 \%$ for Brazil. To calibrate the process for the policy-controlled interest rate, we estimate a first-order autoregressive process on $\hat{\imath}_{t}^{g}$, an interest rate differential between the money market rate in a given country and a U.S. Federal Funds rate for a panel of three countries. We restrict this process to be the same across the three countries we consider. This approach is intended to capture the dynamics of $\hat{\imath}_{t}^{g}$ in an average emerging market economy. It also allows us to isolate cross-country differences in exchange rate dynamics driven by a limited set of structural country characteristics. We find $\rho^{g}=0.92$ and $\sigma\left(\varepsilon_{t}^{g}\right)=0.0413 .{ }^{27}$ Finally, we also calculate country-specific values for the lump-sum transfers from the government to the private sector, $\bar{\tau}$. As before, we measure $\bar{\tau}$ as the average ratio of government consumption to GDP over the corresponding sample period. The new parameter values are summarized in Table 2.

We solve the model under these new parameterizations and generate the responses of the exchange rate to the interest rate innovations. The resulting impulse responses along with the corresponding data impulse responses are presented in Figure 8.

Figure 8 shows that our model delivers impulse responses that qualitatively match those in the data: The exchange rate appreciates in Thailand, depreciates in Korea, and exhibits no significant change in Brazil following a one standard deviation innovation to interest rate. The opposing responses of exchange rates in Korea and Thailand are especially striking given that the two countries

\footnotetext{
${ }^{25}$ The numbers for private credit to GDP in Thailand, Korea and Brazil are borrowed from the Financial Structure Dataset assembled by Beck, Demirgüç-Kunt and Levine (2000) as in the case of Argentina. The share of business credit in total private credit is calculated using the financial institutions reports from the Bank of Thailand, Korea and the Central Bank of Brazil. These numbers are $66 \%$ for Korea, $67 \%$ for Thailand, and $78 \%$ for Brazil. The reserve requirement ratios for these countries are calculated following Brock (1989). See web appendix for detailed data sources (available at http://www.econ.ubc.ca/vhnatkovska/research.htm). We also raise the value of $\phi^{n}$ for Thailand to 0.13 from 0.10 in order to ensure that the relevant interest rate spreads remain positive.

${ }^{26}$ We should note that due to the small number of observations in the 1997-2001 subsample we had to use monthly data in our empirical VARs. We continue using monthly data in our empirical estimation on the full 1997-2007 sample in order to retain comparability of results.

${ }^{27}$ We also estimated country-specific processes for $\hat{\imath}^{g}$, and found them to be along the lines of the aggregate estimates.
} 
are very similar along a number of dimensions: the steady state levels of $i^{g}$ and $\tau$; the process for $i^{g}$; as well as most of the structural parameters. The key difference between the two countries in the context of our model is in the level of business loans to GDP, captured by the parameter $\phi$. This parameter determines the strength of the output effect through working capital cost; and affects the intensity of the money demand effect through the steady state levels of interest rates in the model. In Thailand, where the share of private credit is larger, the money demand effect of $\phi$ dominates and the exchange rate appreciates. The opposite is true in Korea leading to depreciated exchange rate.

The success of our model, however, is not limited to capturing the behavior of exchange rate. We want to ensure that matching dynamics of exchange rates in our model does not come at the expense of unrealistic dynamics of other variables. This is not the case. We again return to the empirical VARs estimated at the beginning of the paper. Besides the exchange rate the estimated VAR systems also included output and fiscal balance to capture, respectively, the output and fiscal effect of interest rate changes. Here we present the empirical impulse responses of output and fiscal balance and compare them with their theoretical counterparts. Figure 9 shows the impulse response of output to interest rate shocks, while Figure 10 shows the corresponding impulse responses for the fiscal balance in the three countries. The left-hand-side panel of Figure 9 shows that both Korea and Brazil experienced a contraction in industrial production following a positive interest rate innovation. The output response in Thailand is more mixed as it fluctuates around zero. The right-hand-side panel of Figure 9 shows that in the model Thai, Korean and Brazilian output decline after a positive interest rate shock. The figures suggest that the model does well in reproducing the output response in Korea and Brazil to interest rate innovations while it fails to do so for Thailand.

Figure 10 shows the response of the fiscal balance to a positive innovation in the interest rates in our three countries. The model produces a worsening fiscal balance in all three countries while in the data the evidence is mixed. The fiscal balance worsens in Korea, improves in Thailand and fluctuates around zero in Brazil. While the model doesn't reproduce the fiscal responses in Brazil and Thailand, it does reproduce the ordering of the fiscal responses.

\subsection{Stable period}

In this subsection we aim to verify whether our model is successful in capturing the interest rateexchange rate interplay when interest rates instruments are not actively used by a country's policymakers. For this purpose we repeat the exercise in the previous subsection for the full sample of 
1997-2007. Table 3 summarizes the updated model parameters.

The key difference from the parameters in the short sample is lower steady state level for $i^{g}$, as well as more stable dynamics for $i^{g}$ in all three countries. Furthermore, Thailand and Brazil experienced a fall in the share of business sector credit in total credit, which lead to lower parameter $\phi$. That number for Korea became slightly higher. We also re-calibrate the process for $i^{g}$ and find $\rho^{g}=0.95$ and $\sigma\left(\varepsilon_{t}^{g}\right)=0.0276$. As before, we restrict this process to be the same across our three economies. Lastly, we set $\phi^{n}=0.14$ in all three countries.

Figure 11 contrasts the empirical and model-generated impulse responses of the exchange rate to interest rate shocks. In the data the exchange rate depreciates in response to an increase in the interest rate for all three countries. The model impulse responses replicate precisely this pattern as well as the size-ordering of the individual country responses.

We also compare the model and data impulse responses of output and the fiscal balance to interest rate innovations in these countries. The left panel of Figure 12 shows the data impulse response of output to a one standard deviation interest rate innovation while the right panel shows the corresponding impulse responses generated by the model. Both in the model and the data output falls on impact in all three countries. As in the shorter sample, the model does well in reproducing the data in terms of the response of output to interest rate innovations in Brazil and Korea but fails to pick up the relative lack of a response in Thailand.

Figure 13 depicts the data and model generated impulse response for the fiscal balance. For all three countries the fiscal balance clearly worsens on impact both in the data and the model.

Overall, we interpret the evidence in Figures 8-13 as being supportive of the margins isolated in the model. Given that the model was not calibrated to match impulse responses and the fact that the parameterization was changed along just three dimensions for these three countries, we find the results to be very encouraging for the ability of the model to explain exchange rate dynamics in different countries.

\section{Conclusions}

To be completed. 


\section{References}

[1] Beck, T., A. Demirgüç-Kunt, and R. Levine, 2000, "A New Database on Financial Development and Structure," World Bank Economic Review 14, 597-605.

[2] Brock, P. L., 1989, "Reserve Requirements and the Inflation Tax," Journal of Money, Credit and Banking 21 (1), 106-121.

[3] Calvo, G. and C. Reinhart, 2002, "Fear of Floating," Quarterly Journal of Economics 117, $379-408$.

[4] Calvo, G. and C. Végh, 1995, "Fighting Inflation with High Interest Rates: The Small Open Economy Case under Flexible Prices," Journal of Money, Credit, and Banking 27, 49-66.

[5] Correia, I., J. Neves, and S. Rebelo, 1995, "Business Cycles in a Small Open Economy," European Economic Review 39 (6), 1089-1113.

[6] Diaz-Gimenez, J., E. Prescott, T. Fitzgerald, and F. Alvarez, 1992. "Banking in Computable General Equilibrium Economies," Journal of Economic Dynamics and Control 16 (3-4), 533559.

[7] Drazen, A. and S. Hubrich, 2006, "A Simple Test of the Effect of Interest Rate Defense," NBER Working Paper W12616.

[8] Druck, P. and P. Garibaldi, 2000, "Inflation Risk and Portfolio Allocation in the Banking System," mimeo (IMF and UCLA).

[9] Easterly, W., P. Mauro, and K. Schmidt-Hebbel, 1995, "Money Demand and SeigniorageMaximizing Inflation," Journal of Money, Credit, and Banking 27, 583-603.

[10] Edwards, S. and C. Végh, 1997, "Banks and Macroeconomic Disturbances under Predetermined Exchange Rates," Journal of Monetary Economics 40, 239-278.

[11] Eichenbaum, M. and C. Evans, 1995, "Some Empirical Evidence on the Effects of Shocks to Monetary Policy on Exchange Rates," Quarterly Journal of Economics 110 (4), 975-1009.

[12] Greenwood, J., Z. Hercowitz and G. Huffman, 1988, "Investment, Capacity Utilization, and the Real Business Cycle," American Economic Review 78, 402-417. 
[13] Judd, K. L. (1998). "Numerical Methods in Economics", MIT Press, Cambridge, Massachusetts.

[14] Kiguel, M., 1989. "Budget Deficits, Stability and the Monetary Dynamics of Hyperinflation," Journal of Money, Credit and Banking 21 (2), 148-15\%.

[15] Kraay, A., 2003, "Do High Interest Rates Defend Currencies During Speculative Attacks?", Journal of International Economics, 59 (2), pages 297-321.

[16] Meese, R., 1990, "Currency Fluctuations in the Post-Bretton Woods Era", Journal of Economic Perspectives 4, 117-134.

[17] Mendoza, E. G. (1991). "Real Business Cycles in a Small Open Economy", American Economic Review 81 (4), 797-818.

[18] Moore, G. R., R. D. Porter, and D. H. Small, 1990, "Modeling the Disaggregated Demands for M2 and M1: the U.S. Experience in the 1980s," in P. Hooper et. al., eds., Financial Sectors in Open Economies: Empirical Analysis and Policy Issues (Washington, D.C.: Board of Governors of the Federal Reserve System, 1990).

[19] Neumeyer, P. A. and F. Perri, 2005, "Business Cycles in Emerging Economies: The Role of Interest Rates," Journal of Monetary Economics, 52 (2), 345-380.

[20] Obstfeld, M. and K. Rogoff, 2000, "The Six Major Puzzles in International Macroeconomics: Is There a Common Cause?" NBER Macroeconomics Annual, 15, 339-390.

[21] Rebelo, S. and C. Végh, 1995, "Real Effects of Exchange Rate-Based Stabilizations: An Analysis of Competing Theories," NBER Macroeconomics Annual, 125-174.

[22] Rodriguez, C. A., 1991, "Financial Reform and Macroeconomic Developments in Argentina, Chile, and Uruguay during the Decade of the 1980's," mimeo (Universidad del CEMA, Buenos Aires).

[23] Schmitt-Grohe, S. and M. Uribe, 2004, "Solving Dynamic General Equilibrium Models Using a Second-Order Approximation to the Policy Function", Journal of Economic Dynamics and Control, 28, 755-775.

[24] Uribe, M. and V. Z. Yue, 2006, "Country Spreads and Emerging Countries: Who Drives Whom?", Journal of International Economics, 69, 6-36. 
Figure 1. VAR: Nominal exchange rate response to interest rate innovations
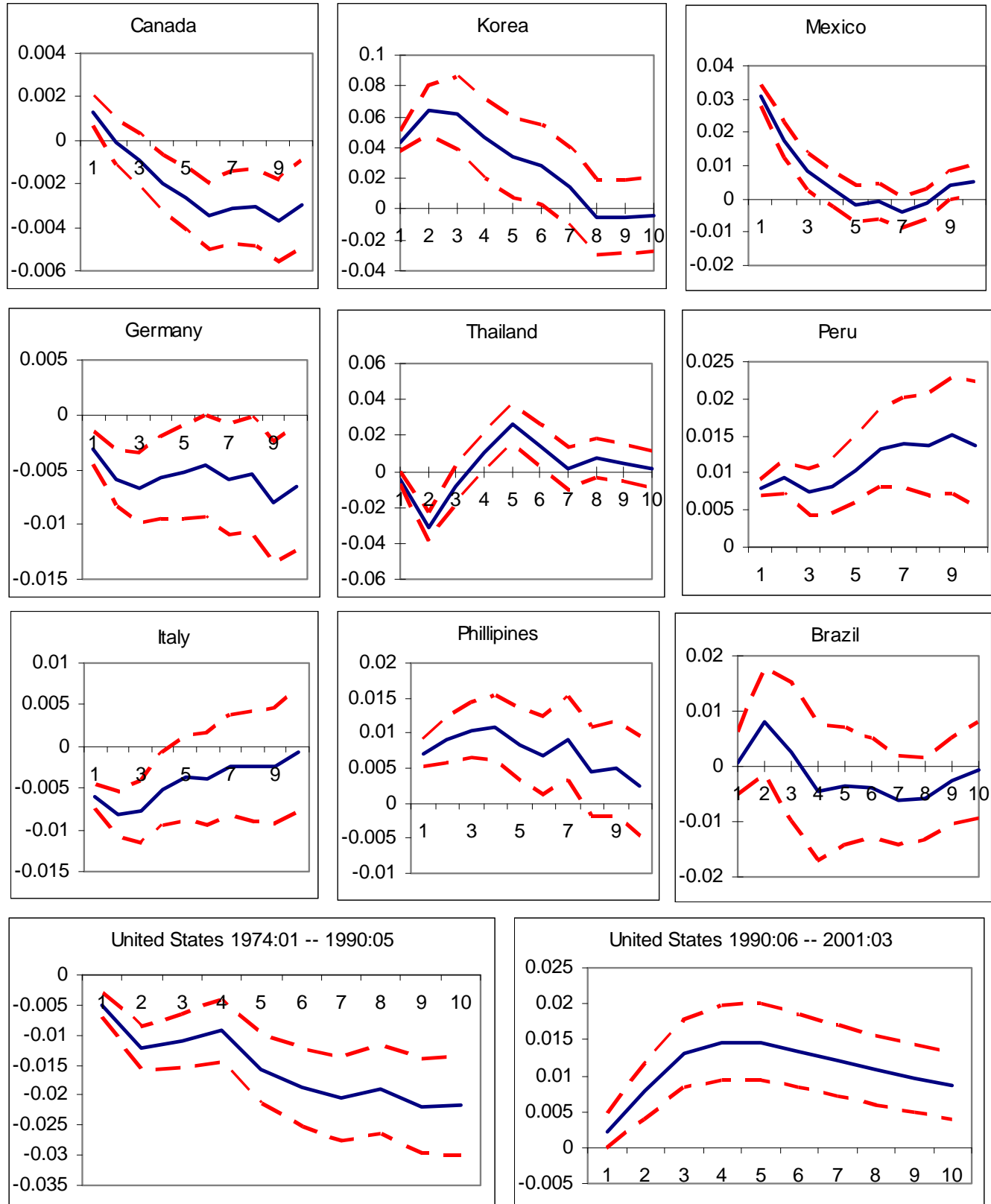
Table 1. Benchmark parameter values

\begin{tabular}{llc}
\hline \hline PREFERENCES & & \\
discount factor & $\beta$ & 0.971 \\
risk-aversion & $\sigma$ & 5 \\
labor curvature & $v$ & 1.6 \\
labor weight & $\zeta$ & 2.48 \\
\hline TECHNOLOGY & $\alpha$ & 0.38 \\
capital income share & $\delta$ & 0.044 \\
depreciation rate & $\phi$ & 0.26 \\
share of wage-in-advance & $\xi$ & 4.5 \\
capital adjustment costs & $\phi^{n}$ & 0.4 \\
\hline MONEY & $\theta$ & $10, s_{d}=5$ \\
reserve requirement & $\sum_{\varkappa=h, d} s_{\varkappa}\left(\varkappa^{2}-\varkappa+1 / 4\right)$ & 1 \\
transaction cost technology & & 0.1 \\
banks cost technology & $\gamma$ & \\
per unit loans costs & & \\
\hline \hline
\end{tabular}

Figure 6. Transitions: Different steady state $i^{g}$
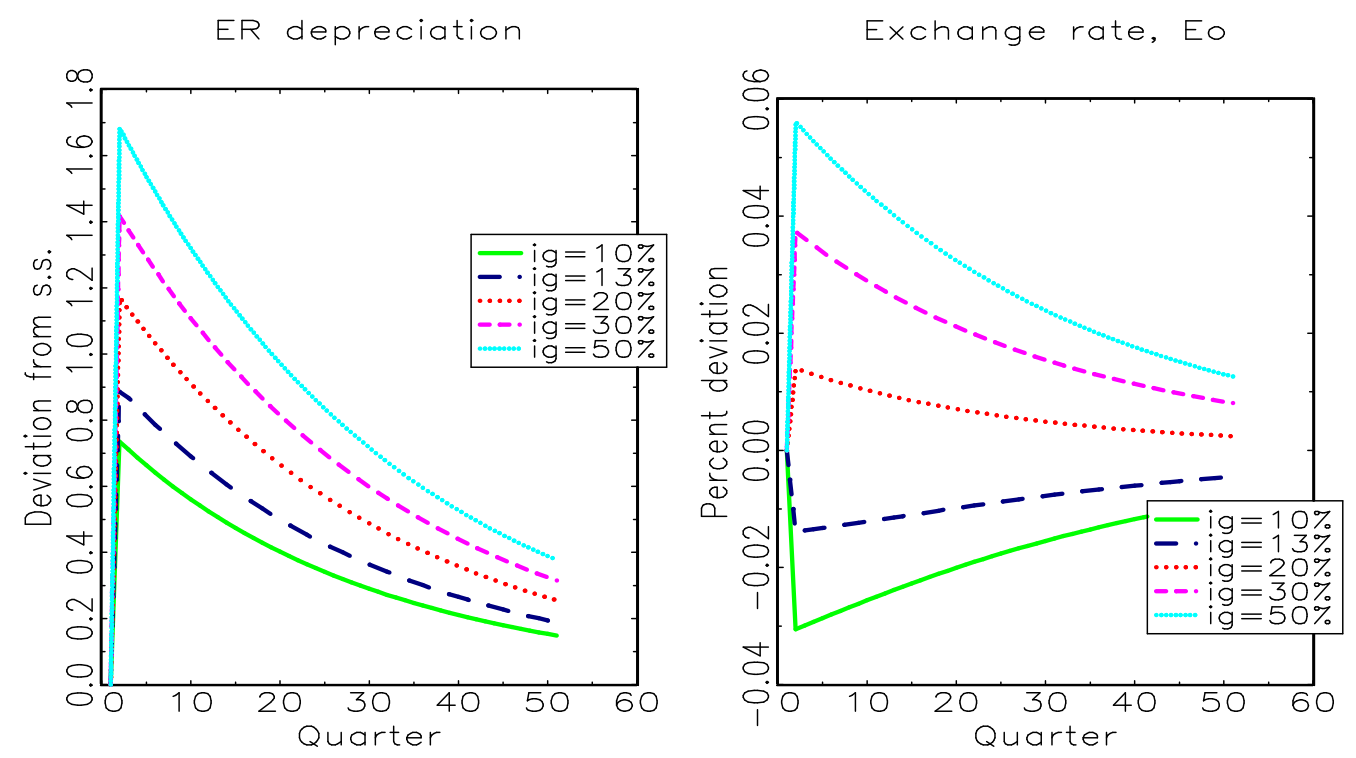
Figure 7. Transitions: Different size of shocks to $i^{g}, i_{s s}^{g}=13 \%$.
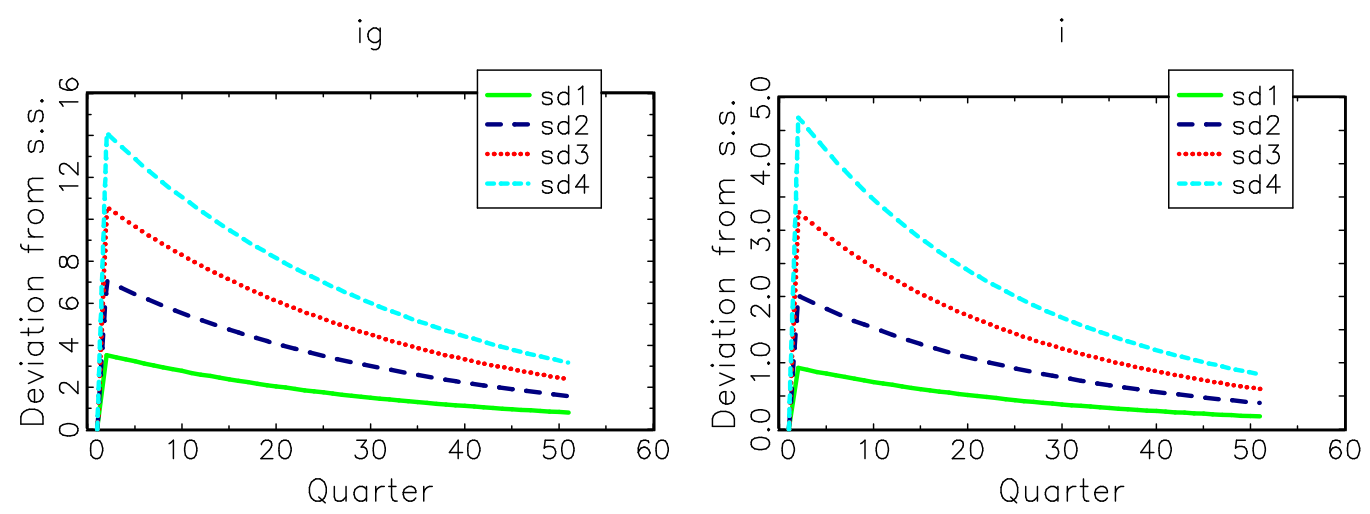

ER depreciation

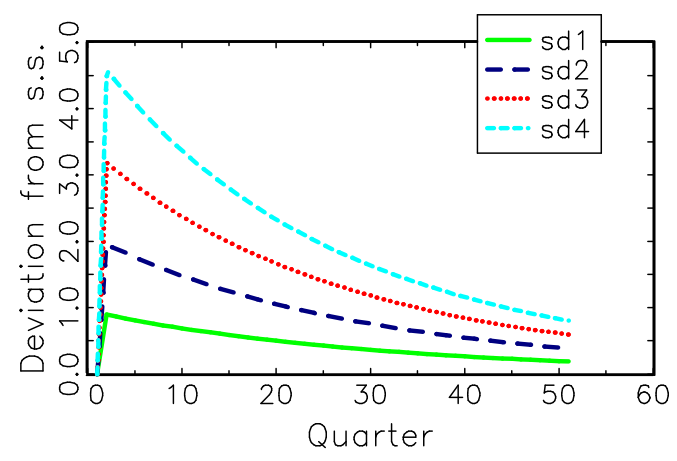

Exchange rate, Eo

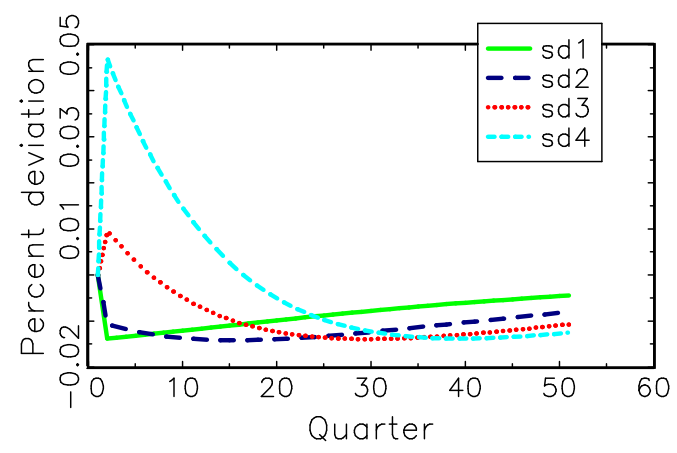

Table 2. Parameter values: Thailand, Korea, Brazil for 1997-2001

\begin{tabular}{lccc}
\hline \hline & Thailand & Korea & Brazil \\
share of wage-in-advance, $\phi$ & 1.11 & 0.72 & 0.36 \\
reserve requirement, $\theta$ & 0.03 & 0.03 & 0.27 \\
Average $i^{g}$ & $7 \%$ & $9 \%$ & $23 \%$ \\
Average $\tau$ & $11 \%$ & $12 \%$ & $20 \%$ \\
\hline \hline
\end{tabular}


Figure 8. Exchange rate impulse responses for Thailand, Korea and Brazil 1997-2001
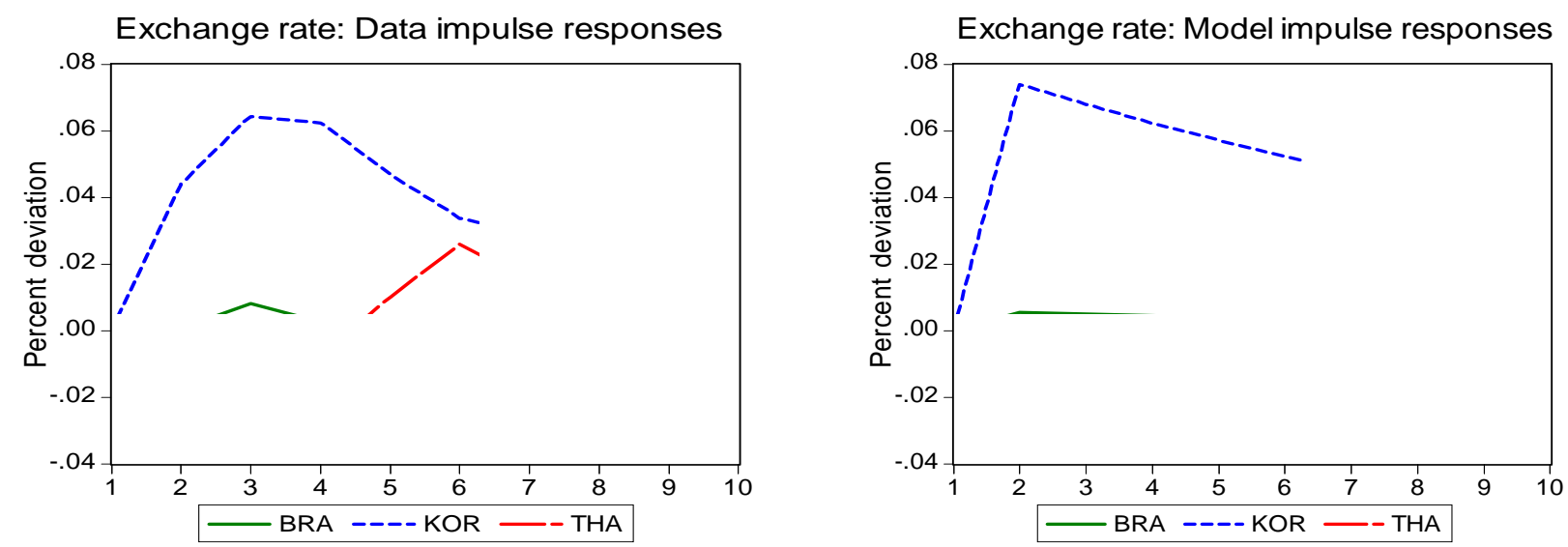

Figure 9. Output impulse responses for Thailand, Korea and Brazil 1997-2001
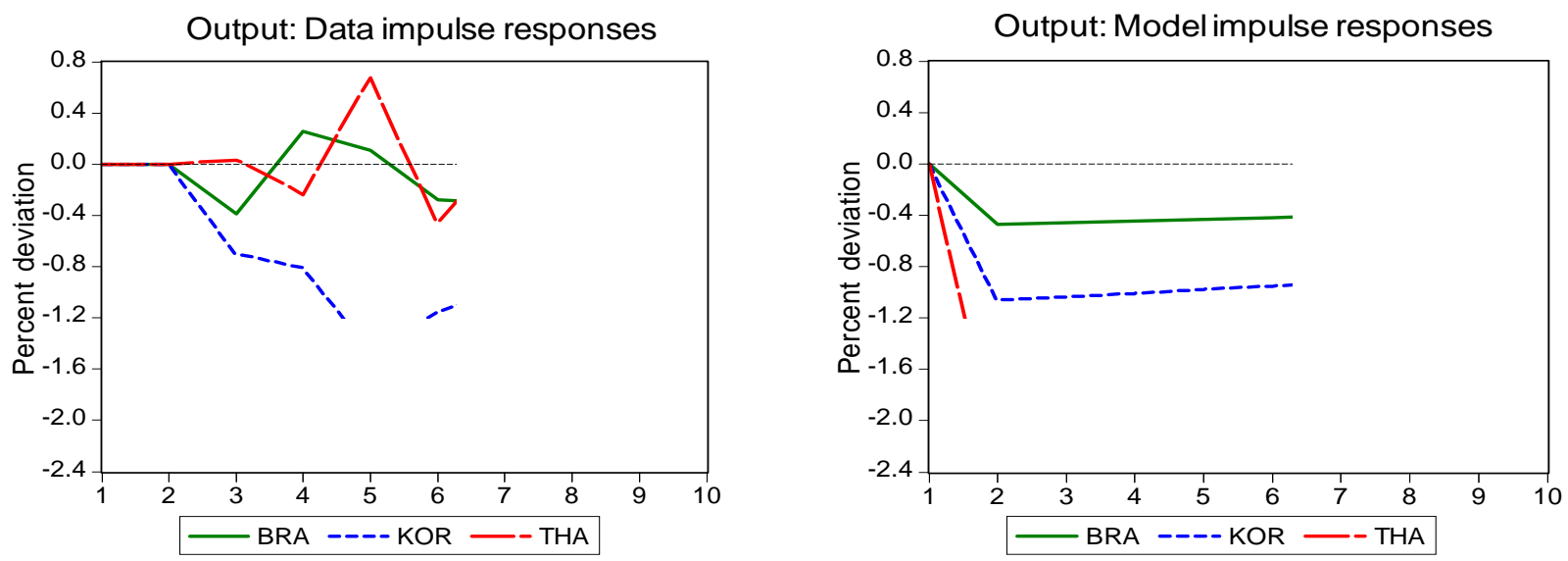

Figure 10. Fiscal balance impulse responses for Thailand, Korea and Brazil 1997-2001
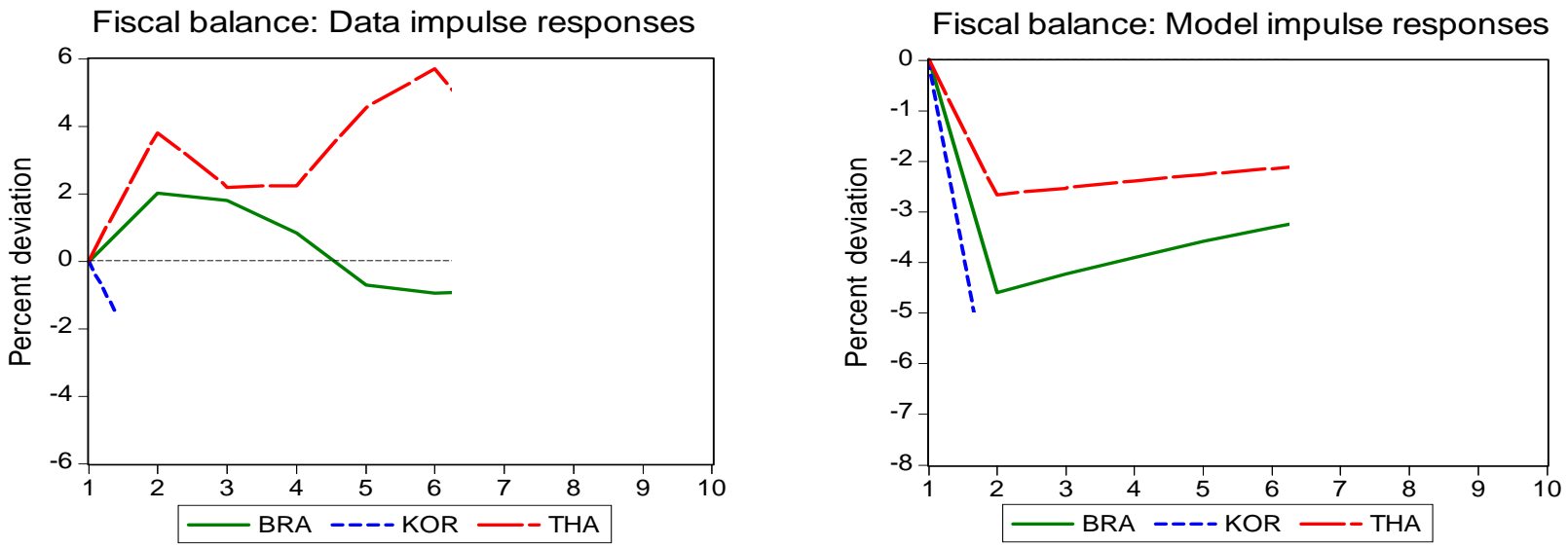
Table 3. Parameter values: Thailand, Korea, Brazil for 1997-2007

\begin{tabular}{lccc}
\hline \hline & Thailand & Korea & Brazil \\
share of wage-in-advance, $\phi$ & 0.9 & 0.73 & 0.31 \\
reserve requirement, $\theta$ & 0.03 & 0.03 & 0.176 \\
Average $i^{g}$ & $4.1 \%$ & $6 \%$ & $19 \%$ \\
Average $\tau$ & $11 \%$ & $13 \%$ & $20 \%$ \\
\hline \hline
\end{tabular}

Figure 11. Exchange rate impulse responses for Thailand, Korea and Brazil 1997-2007
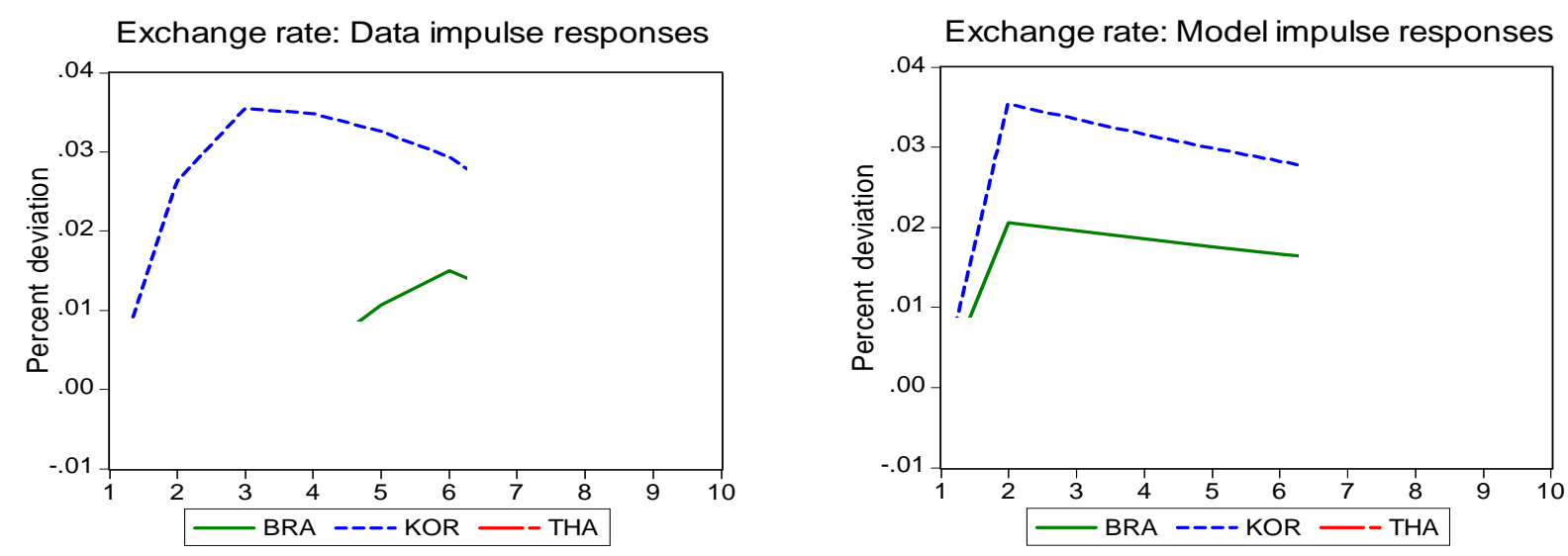

Figure 12. Output impulse responses for Thailand, Korea and Brazil 1997-2007
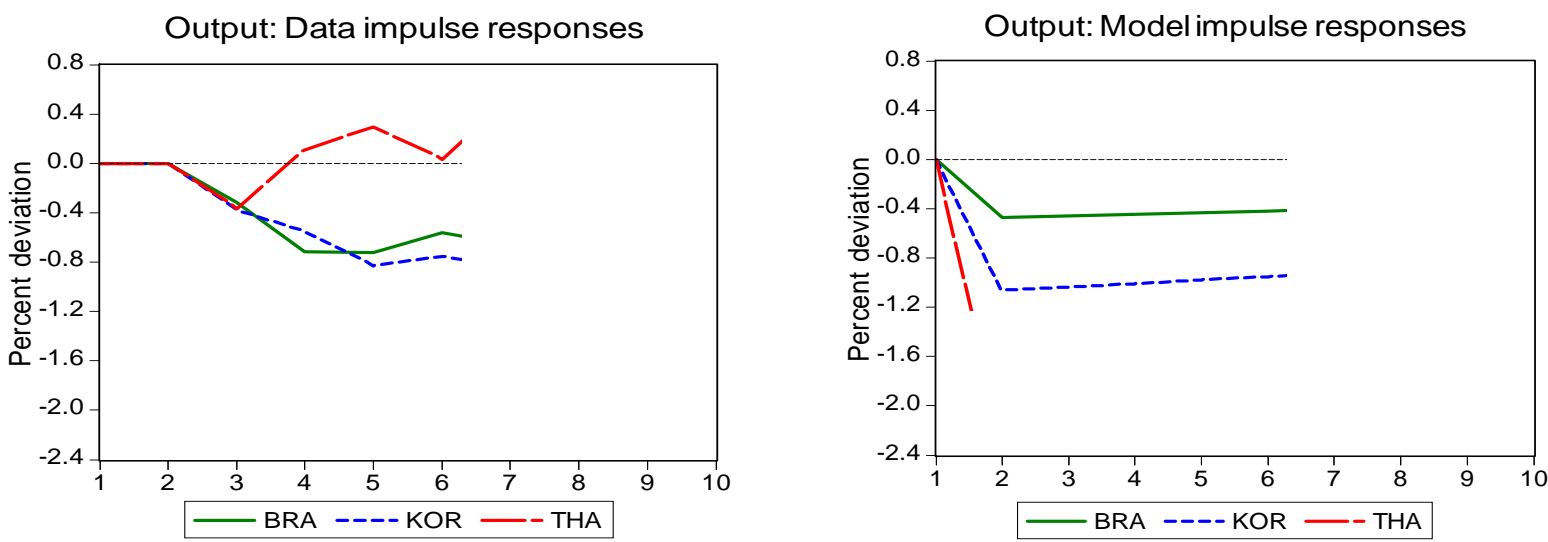
Figure 13. Fiscal balance impulse responses for Thailand, Korea and Brazil 1997-2007
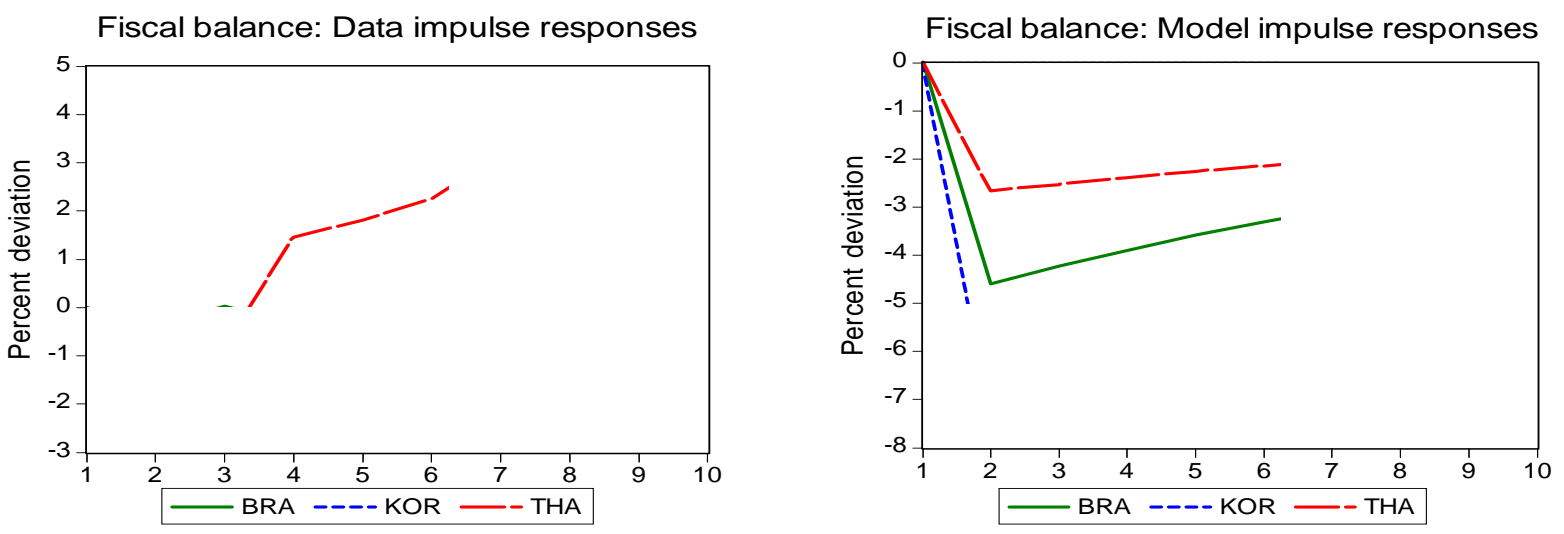